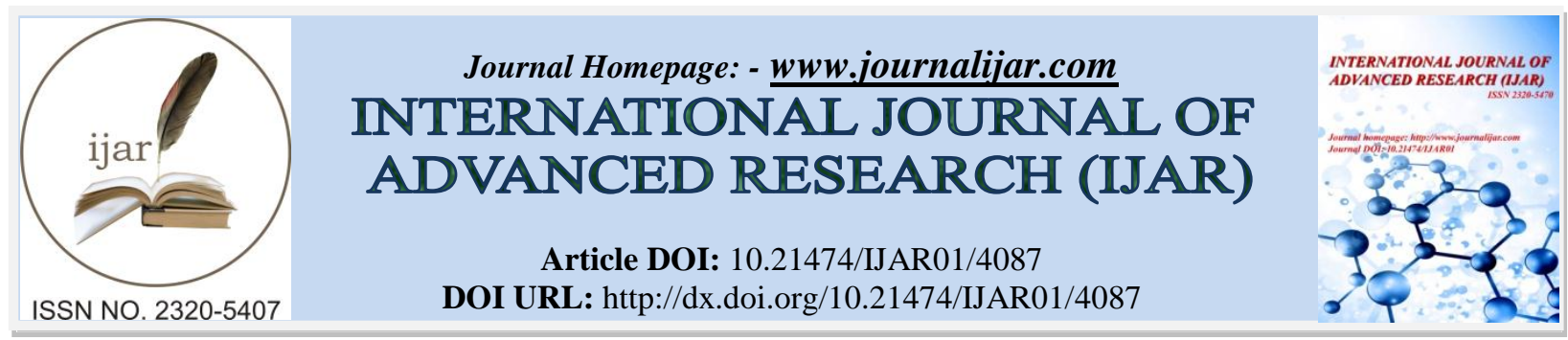

RESEARCH ARTICLE

\title{
ARM 7 BASED AUTOMATIC VEHICLE SPEED CONTROLLER WITH TELEMTRY AND TRACKING SYSTEM.
}

*Anju Poulose, B Aliya Thaslim, Darshini N and Niranjan Kr Singh.

Electronics and communication Engineering Department SaIT Bangalore.

\section{Manuscript Info}

Manuscript History

Received: 09 March 2017

Final Accepted: 01 April 2017

Published: May 2017

\begin{abstract}
Today accidents occur frequently, causing the death of many people because of making mistakes while driving modestly (in a school zone, on hills and highways). But sometimes you cannot see the signs placed by the Ministry of the road to alert the drivers in these places and there is a possibility of an accident. The main goal is to design the electronic lcd to control and behold the speed zones of the vehicle, which runs on an integrated system and can be customized to fit the vehicle dashboard to display information about the vehicle. The project consists of two separate units: the transmission state of the zone with control unit and the electronic display unit. Vehicle telemetry and tracking system designed to assist the traffic system by providing information about the vehicles to the traffic police. The location of the vehicle is located using the GPS receiver in the car and is displayed on the LCD screen so that we can know where we are. The alcohol sensor is used to measure the concentration of alcohol in the body.
\end{abstract}

Copy Right, IJAR, 2017,. All rights reserved.

\section{Introduction:-}

It is evident that traffic accidents are increasing day by day. Recent studies show that one-third of the deaths associated with speeding in places where there are sharp turns and passages, as well as changes in the road or due to the presence of unexpected obstacles. This is due to having to wait for hours in the traffic jams, detours due to tortuous road works, trying to detect speed switches, turns with blind navigation, single track and so on. Roads, division level steps, curves and sudden changes, steep descents and rises are some of the peculiarities of the road that can be found in the average unit. Such path peculiarities indicated by traffic signs. Mandatory traffic lights enforce traffic laws; warning signs are installed in hazardous areas to prevent accidents. Traffic information signs provide directions, places, and other potentially useful information for drivers in this location. However, most vehicle drivers lose traffic lights more often. It is difficult to keep an eye on traffic lights when you should focus on driving. Many driver assistance systems for speed control have been developed to avoid accidents. One of these is the cruise control system (ccs) which is able to maintain the speed and the adaptive cruise control (acc) then keeps the car at a predetermined distance of the vehicle safely. However, these systems do not detect the curvy roads, where the speed of the vehicle must be reduced to avoid accidents. Then the curve alarm systems (cfs) have been created to detect curved trajectories using the global positioning system (gps) and digital maps that can be accessed from the geographic information systems (gis) to warn the driver to approach the curve of the road. However, these maps need to be updated regularly and are not useful if unpredictable detours or traffic accidents. We offer you a dynamic model in which the system controls the vehicle according to the data frame is transmitted by the RF transmitter attached to the nearby traffic lights. The data frame is received by the micro-controller which controls 
the speed of the vehicle. There is an intelligent vehicle speed control system based on RF id passive RF transceivers are arranged on the road near the position of the actual traffic signals. This model can also be best used to improve energy efficiency by imposing the maximum speed limit on cars in the city.

\section{Details experimental:-}

Proposed system:-

The main purpose is to replace traffic signals with tags, and the use of drive modules enabled to detect and provide information useful for controller design and electronic control screen to control vehicle speed is a system integrated. The tag may be placed on an existing roadway signal for the transmission of traffic information signals arranged to adjust the speed of the vehicle. On receiving the information on the label, the electronic control display vehicle automatically warns the driver to reduce the speed depending on the road signal indicated by the RF tag. Wait for a few seconds for the controller response to the received information, otherwise the vehicle automatically breaks EDC unit. The area between two labels where it is controlled or speed is reduced is called an access point. The installation of a headlamp a few kilometers before the fault zone can be used to prevent appropriate deviations. Care must be taken to provide priority alerts. The whole operation of the prototype is shown and the system cannot operate due to the large distance of the satellite signal or weak RF signals can still be transmitted reliably under all conditions. Driving safety is increased and provides a positive additional cost to the government. In this prototype, it is only considered a vehicle. Virtually other moving vehicles can block near or attenuate RF signals. If the speed of the cabin exceeds $20 \mathrm{~km}$ (or $30,40.50$, etc.) and then the vehicle speed is controlled by the control. If the vehicle speed is less than $20 \mathrm{~km}$ (less than the specified speed limit zones), the process control will be ignored.

\section{Telemetry and Tracking System:-}

A potentiometer is used to simulate a speed sensor. If the speed exceeds the limit, a signal for the server traffic is sent to other measurements. The vehicle may be blocked by server traffic if certain rules are broken by the vehicle. And to unlock the vehicle owner must pay the fine and the vehicle is unlocked by traffic server. This unlocking process is done using the RF signal server system with traffic police. When the driver gets into the vehicle he has to take the test to check if he has drunk. Alcohol sensor is used to measure the concentration of alcohol in their bodies. If the concentration is higher, the ignition system is deactivated and if it less than the threshold level ignition system is activated. 
Flowchart:-

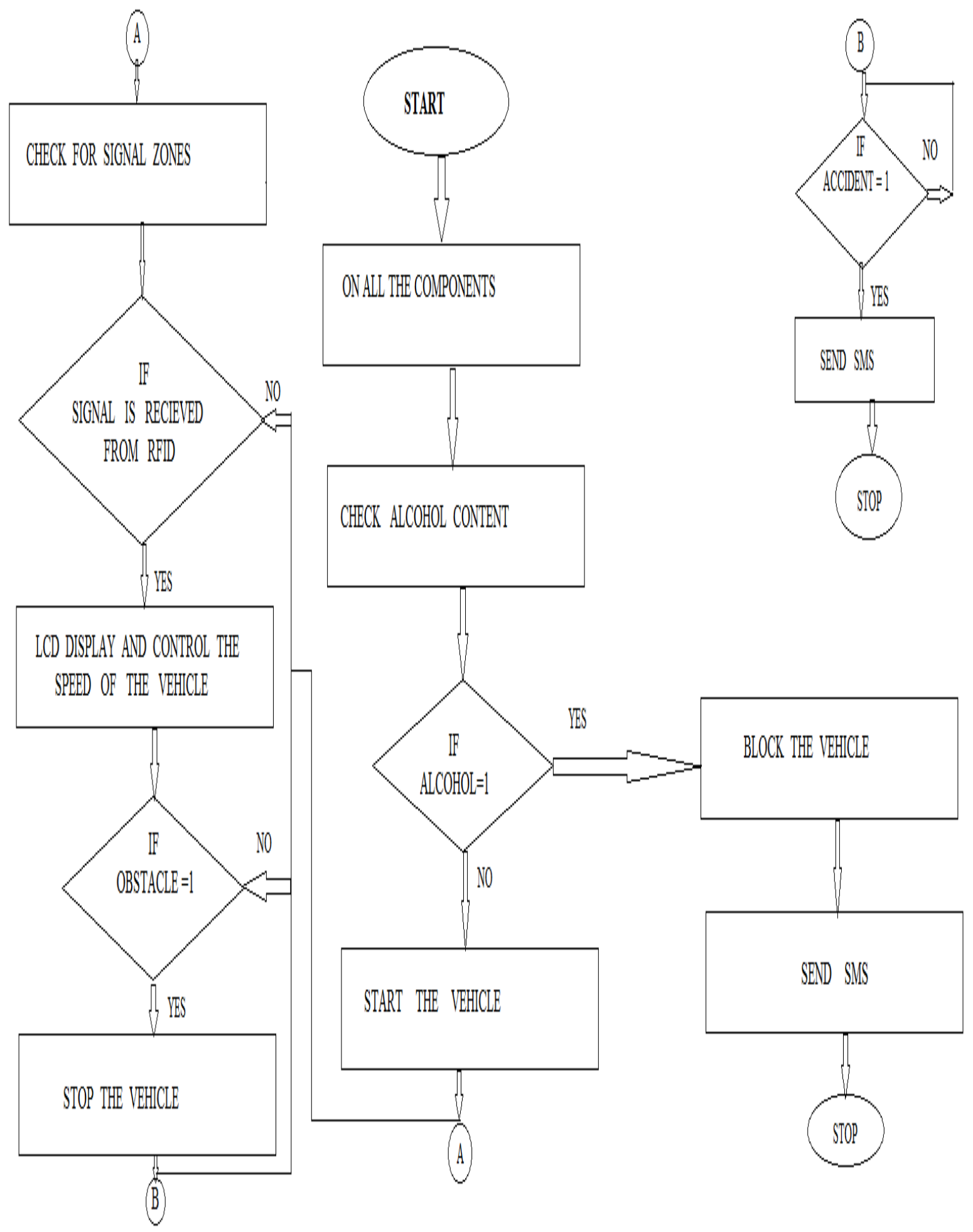




\section{Acknowledgment:-}

The satisfaction of recognition and the euphoria that accompanied the success of any project will not be complete without mentioning the people who helped with the advice and the constant encouragement of our successful efforts. We want to take this opportunity to express our deep gratitude to all those who have supported us directly or indirectly to the success of the project. Thank you Director Dr.H.G.Chandrakanth Principal, Sambhram Institute of Technology, Bangalore-97, for all the equipment provided. Dr.Ravishankar Dept. of ECE, for your support and encouragement was a long way to the success of this work project. We consider it a privilege to express our sincere appreciation and respect for Prof.Pavana $\mathbf{H}$ Assistant professor, Dept. of ECE for being our internal guide, for their integral and incessant support offered to us throughout the course of this project and for constant source of inspiration throughout the project.

\section{References:-}

1. "Travolution-An Embedded System in Passenger Car for Road Safety"978-1-4799-8187-8/15/\$31.00 @2015 IEEE

2. V RAMYA ;B Palaniappan on Embedded Controller for Vehicle In front obstacle Detection and Cabin Safety Alert system.

3. Maurya, Mandeep Singh, Neelu Jain, "Real Time VehicleTracking System using GSM and GP Technology-An Anti-theft Tracking System “, International Journal of Electronics and Computer Science Engineering, ISSN 2277-1956/V1N3- 1103-1107.

4. R.S Gaonkar , "Microprocessor Architecture Programming ", Wiley Eastern Ltd, New Delhi.Krishna Kant, "Microprocessor and microcontroller", EasternCompany Edition , New Delhi 2007.Daniel. W. Lewis, "Fundamental of embedded software", prentice hall of India, 2004.William Stalling, "Wireless Communication and Networks", $2^{\text {nd }}$ edition, prentice hall of India, 2005

5. Chen, H., Chiang, Y. Chang, F. H. Wang, Toward Real-Time Precise PointPositioning: Differential GPS Based on IGS Ultra Rapid Product, SICEAnnual Conference, The Grand Hotel, Taipei, Taiwan August 1821,(2010).saad M. J. Al-Hindawi, Ibraheem T

6. 11 alib, "Experimentally Evaluation ofGPS/GSM Based System Design", Journal of Electronic Systems, Volume 2Number, 2 June, 2012.Maurya , Mandeep Singh, Neelu Jain, "Real Time Vehicle

7. Tracking System using GSM and GPS Technology- An Anti-theft Tracking

8. System", International Journal of Electronics and Computer ScienceEngineing, ISSN 2277-1956/V1N3-11031107

9. Vikram Kulkarni \& Viswaprakash Babu, "embedded smart car securitysystem onface detection", special issue of IJCCT, ISSN(Online) :2231-0371, ISSN(Print):0975-7449, volume-3, issue-1. 